\title{
O PROBLEMA DA INTRODUÇÃO DAS LÍNGUAS NACIONAIS NO SISTEMA EDUCACIONAL FORMAL DO BENIM: \\ forças e restrições
}

\author{
Julvan Moreira de Oliveira \\ Narcisse Sylvestre Sègla Adjoudeme
}

Resumo

O objetivo deste estudo é mostrar a relevância da introdução das línguas nacionais no sistema de educação formal beninense. Situando-se no campo da Antropologia da Educação (CARVALHO, 1982a; 1982b) e compreendendo que pela língua a educação cultural se transmite, combina o método qualitativo, tendo como amostra 18 pessoas: três funcionários do Ministério da Educação, quatro funcionários da Direção de Promoção de Idiomas, dois pais de alunos e dois técnicos de recursos humanos. A análise dos resultados concluiu que quase todos os entrevistados ressaltaram a introdução das línguas nacionais como de importância capital. O resultado do estudo confirmou, ainda, essa premência. Houve distintas propostas, considerando o vínculo entre a linguagem como vetor para desenvolvimento e a adaptação das realidades endógenas.

Palavras-chave: língua; bilinguismo; multilinguismo

\section{THE PROBLEM OF THE INTRODUCTION OF NATIONAL LANGUAGES IN THE BENIN FORMAL EDUCATIONAL SYSTEM: strengths and constraints}

\begin{abstract}
The aim of this study is to show the relevance of the introduction of national languages in the formal education system in Benin. Situating in the field of Anthropology of Education (CARVALHO, 1982a; 1982b) and understanding that cultural language is transmitted through language, it combines the qualitative method, with a sample of 18 people: three employees from the Ministry of Education, four employees from the Education Directorate Language Promotion, two parents of students and two human resources technicians. The analysis of the results concluded that almost all the interviewees emphasized the introduction of national languages as of major importance. The result of the study also confirmed this urgency. There were different proposals, considering the link between language as a vector for development and the adaptation of endogenous realities.
\end{abstract}

Keywords: language; bilingualism; multilingualism

\section{EL PROBLEMA DE LA INTRODUCCIÓN DE IDIOMAS NACIONALES EN EL SISTEMA EDUCATIVO FORMAL DE BENIN: \\ fuerzas y restricciones}

Resumen

El objetivo de este estudio es mostrar la relevancia de la introducción de idiomas nacionales en el sistema de educación formal en Benin. Situada en el campo de la Antropología de la Educación (CARVALHO, 1982a; 1982b) y entendiendo que el lenguaje cultural se transmite a través del lenguaje, combina el método cualitativo, con una muestra de 18 personas: tres empleados del Ministerio de Educación, cuatro empleados del Dirección de Educación de Promoción del Idioma, dos padres de alumnos y dos técnicos de recursos humanos. El análisis de los resultados concluyó que casi todos los entrevistados enfatizaron la introducción de idiomas nacionales como de mayor importancia. El resultado del estudio también confirmó esta urgencia. 
Hubo diferentes propuestas, considerando el vínculo entre el lenguaje como un vector para el desarrollo y la adaptación de las realidades endógenas.

Palabras clave: idioma; bilinguismo; multilinguismo

\section{INTRODUÇÃO}

Veículo privilegiado para a transferência do conhecimento, a língua desenvolve papel insubstituível na formação de um país (GUEYE, 2010; ROLLAND, 2010). No continente africano, especificamente no Benim, a introdução das línguas nacionais no sistema de educação formal é preocupação fundamental. Para Koil (1967), a educação soma-se à socialização: criança e adulto não podem ser dissociados do meio cultural. Não apenas um complexo de palavras e formas gramaticais, mas, sobretudo, difusora dos conceitos e tradições do grupo social: simultaneamente, a criança adquire a linguagem e assimila o ambiente (CARVALHO, 1986).

No limiar da independência, esperava-se que os Estados do continente africano adotassem novas políticas para garanti-la, ressaltando que a independência deve ser política, econômica, cultural e linguística. Não é possível ser independente se se continua refletindo e expressando por meio de uma língua estranha ao ambiente. Além disso, não permite que se participe de debates relacionados à vida nacional. Infelizmente, distintos países continuaram dependentes do "legado linguístico" do colonizador, como o Benim, onde o francês é o único difusor de educação.

O vento da renovação democrática que libertou a África negra, entretanto, começou com o Benim e atingiu a maioria dos países africanos. Mas o analfabetismo atinge exorbitantes mais de 80\% da população (GUEYE, 2010, p. 14), excluídos dos reais debates, exceto nas poucas intervenções que oferece a programação de estações de rádio públicas.

A maioria dos líderes políticos utiliza os idiomas nacionais para se manifestar publicamente apenas a fim de demonstrar proximidade e laços étnicos e administrativos e transmitir mensagens que desejam popularizar. Os líderes conscientes da situação linguística reconhecem que não existem portadoras de comunicação mais apropriadas do que as línguas nacionais (ADJADOHOUN, 1991).

Nesse sentido, tendo como base a antropologia, analisamos o plurilinguismo no sistema de educação formal do Benim, observando se ele seria uma fonte de bloqueio, pois a maioria da introdução das línguas exige profunda mudança e se as diversas experiências para introdução das línguas nacionais nas escolas encontraram resistências consideráveis, tais como dificuldades de elaboração de material didático e de conceitualização.

\section{REVISÃO DE LITERATURA}

Como as demais ex-colônias francesas, o Benim passou, durante anos, por uma política linguística do colonizador, que refletia a concepção unitária de uma nação que não podia tolerar diferenças culturais. O "imperialismo cultural francês" reproduziu a política adotada na França metropolitana, com o objetivo de negar e depois eliminar as peculiaridades linguísticas. Os métodos para impor o francês como língua escrita oficial foram os mesmos empregados nas demais províncias francesas. Partindo do pressuposto da superioridade do idioma, provocou-se a marginalização das demais línguas, negando até mesmo o nome dos idiomas africanos, designados por dialetos ou expressões idiomáticas.

Falantes dessas línguas são humilhados permanentemente, em particular na escola, onde o uso do francês ressalta que pertencer ao mundo dos alfabetizados se refere a um universo linguístico francofone. Diferentes métodos foram desenvolvidos por inspetores franceses, como 
Monod e Davesne ${ }^{1}$, para convencer os estudantes africanos a usar o francês com a mesma facilidade dos pequenos alunos das metrópoles.

O argumento para julgar a escolha é a multiplicidade de idiomas. Qual escolher sem prejudicar os demais idiomas nacionais? $\mathrm{O}$ francês, pela neutralidade, seria o único elo entre os diferentes grupos.

Deve-se enfatizar que o Benim possui mais de 70 idiomas nacionais. A posição favorável à exclusividade do francês foi igualmente apoiada pelo fato de que somente essa língua permitiria que os beninenses se abrissem ao mundo, em busca da civilização ocidental. Instituições estatais de poder e contrapoder, como governo, Assembleia Nacional, Tribunal Constitucional, Alta Autoridade de Audiovisual e Comunicação, Conselho Econômico e Social, Supremo Tribunal de Justiça etc. têm exclusivamente o francês como meio de comunicação.

No entanto, revalorizar e promover as línguas nacionais sempre foi preocupação para diversos pesquisadores, linguistas e pedagogos em distintas reflexões.

Lietti (1989) responde aos argumentos encontrados apenas no bilinguismo como as principais razões do retardo intelectual e psicológico da criança, principalmente na situação escolar (fracasso e desperdício escolar, afasia, dislexia, idiotice). Segundo a autora, uma criança que muito cedo entra em contato com um segundo idioma nunca o conhecerá.

Para ela, o fenômeno do bilinguismo não impede o desenvolvimento psicológico e intelectual. Pelo contrário, as escolas obrigam os alunos a abandonar o idioma usado com mais frequência, e isso explica os desvios observados.

Siguàn e Mackey (1986) apresentam que o bilinguismo não torna o indivíduo e/ou o aluno estúpidos. O bilíngue possui duas como línguas maternas:

Bilíngue é uma pessoa que, além do primeiro idioma, possui competência comparável em um idioma e é capaz de usar um ou outro em todas as circunstâncias com eficácia semelhante. Embora a definição proposta se refira ao bilinguismo perfeitamente equilibrado, na prática esse bilinguismo perfeito não existe, porque é muito difícil, ou bastante impossível, para alguém, ter a oportunidade de usar dois idiomas nas mesmas situações e com a mesma frequência (SIGUÀN, MACKEY, 1986, p. 20-24).

Sobre a avaliação da competência linguística, os autores afirmam não ser possível uma única avaliação de um sujeito, devendo ser dividida em diferentes poderes especiais. O sucesso de um programa de educação bilíngue seria possível graças à consideração efetiva de treinamento e desenvolvimento do corpo docente; produção e divulgação de material didático; estabelecimento de centros com características semelhantes às dos centros de educação comum; avaliação e pesquisa contínuas.

Enfatizam (1986, p. 20) que o sistema pode:

[...] decidir dar aos alunos competência completa e equilibrada nos dois idiomas; oferecer apenas uma introdução ao conhecimento e uso de um segundo idioma; que prestem a mesma atenção aos dois idiomas e aos assuntos do programa distribuídos equilibradamente; e que o idioma com o menor cuidado é usado apenas na primeira parte do programa etc. (SIGUÀN, MACKEY, 1986, p. 20).

Adjibodou (2006) indica o espaço das línguas nacionais na sociedade beninense. Segundo o autor, a maioria dos africanos, antes de ir para a escola, adquire e fala os idiomas dos pais, que geralmente representam as linguagens básicas de comunicação. O primeiro reflexo da criança em determinado ambiente é se comunicar com o idioma nacional ali utilizado. Em casa, na vizinhança,

1 Théodore André Monod (1902-2000) e André Prosper Davesne (1898-1978) elaboraram os primeiros manuais de leitura utilizados por estudantes nas escolas africanas. 
com amigos, em pequenas trocas comerciais imediatas, a criança se vale primeiramente da linguagem falada em seu ambiente.

A situação significa que, em nível mais avançado, as trocas ocorrem com maior frequência nas línguas nacionais - no comércio, entre a população, na cidade e no campo.

Em seu estudo, Adjibodou (2006) prossegue no uso das línguas nacionais como meio ou objeto de aprendizado, e consegue diferir entre usar as línguas africanas na escola como objeto de ensino/aprendizagem ou meio de ensino/aprendizagem. Menciona que a introdução de línguas nacionais na escola deveria fornecer, no programa para crianças em idade escolar e alunos, horas de aulas em línguas nacionais.

O uso das línguas nacionais como objeto deveria reservar-lhes um crédito por hora, do mesmo modo que outros assuntos - matemática, ciências físicas, ciências da vida e da terra, ciências sociais etc. O início da aplicação da opção deu-se com os Novos Programas de Estudo no Benim, nos quais há um Módulo de Idioma e Cultura. Nele, os alunos se expressam nos idiomas nacionais.

Pode-se também optar pelo uso de idiomas nacionais na escola como meio de ensino/aprendizagem. Nesta perspectiva, é uma questão de usar idiomas nacionais para fazer tudo: ensinar matemática, ciências físicas, ciências da vida e da terra, ciências sociais e todas as outras disciplinas a serem ensinadas na escola. Essas línguas, portanto, servem como suporte de trabalho linguístico. (ADJIBODOU, 2006, p. 24)

Adjibodou (2006) defende o uso das línguas nacionais como meio de ensino/aprendizagem, sendo difícil perceber como melhorar a situação linguística concedendo créditos por hora para o ensino/aprendizagem nas línguas nacionais. As experiências têm o mérito de possibilitar citar os iniciadores como promotores de idiomas nacionais por sua audácia e investimentos.

Esse ponto de vista é compartilhado por Calvet (1992, p. 23), que ressalta: “[...] a situação na África não é boa, a situação da escola em particular, e é difícil ver como resolver o problema injetando créditos adicionais".

A afirmação é apoiada por Diki-kidiri (1992, p. 26) que declarou:

[...] se alguém estiver satisfeito em considerar o ensino das línguas nacionais como ajuda fornecida aos alunos no primeiro ano de escolaridade, transformamos essas línguas em um banco feito para acessar o francês, por mais que neguemos sua própria existência.

A mensagem oral e escrita na segunda língua implica três dificuldades: decodificação dos gráficos; incompreensão do significado das palavras que deve decifrar; e a mídia.

Para concluir, Diki-kidiri (1992) se pergunta sobre o idioma usado para o ensino/educação. E adota a solução de Hazoumé (1994) que, após ter exposto distintos desenvolvimentos relativos à política linguística do Benim, propõe o seguinte diagrama sobre a escolha de idiomas:

\section{Região Sul}

- Departamento de Ouémé: línguas Gun e Iorubá;

- Departamento do Atlântico: língua Fon;

- Departamento de Zou: línguas Fon e Iorubá;

- Departamento Mono: linguagens Gen e Aja. 


\section{Região Norte}

- Departamento de Borgou: línguas Baatonum e Dendi;

- Departamento de Atacora: línguas Yom, Dendi, Ditammari e Waama.

Teríamos as seguintes opções finais: Fon, Iorubá, Gen, Aja, Yom, Baatonum, Dendi, Ditammari e Waama.

Akoha (1999, p. 15) enfatiza que o francês e as línguas beninenses "[...] são duas criaturas para se dar bem, mas infelizmente se rejeitam a ponto de ficarem doentes". Na realidade, "[...] o francês e as línguas beninenses se complementam constante e espontaneamente. Essa complementaridade entre as línguas francesa e beninense reflete um bilinguismo de fato que nunca foi levado em consideração como deveria ser, nem por políticos e nem por educadores" (AKOHA, 1999, p. 15).

Afelia (1987, p. 9) acrescenta que "[...] o ensino da língua africana também é essencial e justificado porque é necessário democratizar o conhecimento". O acesso ao conhecimento no próprio idioma permite que os alunos orientem a visão política de desenvolvimento.

Além disso, Boko (2007, p. 6) destaca a importância da língua materna no crescimento do indivíduo:

[...] quando a língua materna é impedida de ser exteriorizada pela criança, todo o sistema neurológico fica confuso e o córtex não pode mais regular o fluxo nervoso que deve estimular os músculos da laringe, da boca, língua e mandíbulas [...] deve-se lembrar aqui, simplesmente, que mesmo os agregados de personalidade são hipotecados.

Há ainda o problema da taxa de reprovação escolar e atrasos, cada vez mais altos, e queda drástica no nível dos alunos beninenses na língua da instrução. Segundo Boko (2007, p. 12), os problemas têm origem:

[...] na recusa da escola em admitir a língua materna do aluno. A escola beninense cria um grau significativo de trauma psicológico na criança (neste caso, o da África), quando impedida de falar a própria língua, apagando a retaguarda antecedentes dos pré-requisitos que estruturam todo o seu sistema de cognição.

A linguagem é elemento essencial que permite aos alunos mergulhar em sua cultura, penetrá-la sem confrontos e extrair recursos. Somente a educação em idiomas nacionais superaria o desequilíbrio entre comunidade e intelectuais.

Lekoyo (1988) concorda, elencando sugestões relevantes: escolha de um único idioma, harmonia entre o ambiente da criança e a escola; alunos devem começar aprendendo a língua materna assim que entram.

Serão ministradas em dois anos, e o francês no terceiro ano, dispondo a língua nacional como disciplina ao lado do francês. Nas faculdades e escolas secundárias, o idioma nacional escolhido será ensinado da mesma maneira que o segundo idioma estrangeiro — inglês, espanhol ou alemão. Finalmente, uma seção de línguas beninenses deve ser criada na universidade para pesquisas.

Gnaho (2011) faz um balanço do problema do bilinguismo e multilinguismo no contexto escolar no Benim. Mostrou que os alunos beninenses são bilíngues ou multilíngues. Desejam ardente e conscientemente ter habilidades básicas em sua língua materna e mesmo em uma segunda língua beninense. Além disso, mencionou que 30 línguas maternas beninenses foram escolhidas pelos alunos para serem ensinadas nos distintos estabelecimentos.

Seis chamam mais a atenção: fungbe $(37,17 \%)$; dendi $(13,35 \%)$; iorubá $(9,33 \%)$; ajagbé (7,42\%); gengbé (6,18\%); e baatonu (4,73\%). A partir dos resultados, $90 \%$ dos alunos aprovaram a 
ideia de introduzir as línguas nacionais no sistema educacional. As mais frequentes razões são intercâmbio com os colegas falantes de uma língua que não entendem; assimilar cursos rapidamente, e melhorar o desempenho acadêmico; direito e dever de aprender a ler e escrever na língua materna (GNAHO, 2011).

A procura se manifesta igualmente na alta taxa de inscrição de candidatos para o exame opcional de idioma nacional ao bacharelado.

Leroux (2005) salienta o impacto da Educação Social nos novos programas de estudo sobre promoção e aprimoramento das línguas nacionais, como "campo de treinamento" cujo objetivo é fazer parte de uma perspectiva de desenvolvimento da consciência individual e coletiva do aluno.

Esses novos programas oferecem treinamentos que abrangem áreas da vida cotidiana: "moral individual e vida social"; "sociedade, meio ambiente e desenvolvimento" e "língua e cultura" (LEROUX, 2005, p. 31). O terceiro módulo revela que "língua e cultura" da Educação Social está distante de alcançar os objetivos, não sendo bom presságio para os idiomas nacionais, pois o treinamento oferecido aos professores é insuficiente e mal desenvolvido.

Nem todos os professores conseguiram identificar os três módulos de Educação Social, especialmente o referente ao uso de idiomas nacionais. Desinformados sobre o que ensinar, fornecem aos alunos treinamento de baixa qualidade. Incapazes de apoiar efetivamente os alunos, propõem atividades em idiomas nacionais ou permitem que sejam feitas em francês. Sugere preparar bases para educação bilíngue; fornecer treinamento de qualidade para professores; planejamento linguístico em sala de aula; educar pais; considerar o papel das línguas no desenvolvimento endógeno e no processo de globalização da economia (LEROUX, 2005).

\section{PROBLEMA}

A multiplicidade de línguas não é prerrogativa da África ou do Benim. Faz parte da história recente ou distante de todos os povos do mundo.

A configuração linguística do Benim não é preocupante. As mais de 70 línguas listadas no território poderiam fazer se acreditar em um babelismo nacional, mas não é o caso. Outros países, próximos e distantes, têm grande riqueza linguística considerada "desvantagem" (Papua Nova Guiné, 856 idiomas; Indonésia, 670; Nigéria, 410, Camarões, 270). Há os que têm menos (Angola, 29; Senegal, 20; Mali, 12, e Níger, 10) (OUANE, 1995, p. 174-176).

Nós consideramos importante as possibilidades de envolvimento real de filhas e filhos do país na administração dos assuntos públicos, o que não seria feito sem diálogo com a população e contribuição da reflexão intelectual.

A UNESCO (1953) enfatizou a relevância de educar as crianças na língua materna. O Relatório Global de Monitoramento de Educação para Todos, de 2005, destacou que a escolha do idioma da instrução e da política de idiomas nas escolas desempenha papel essencial na eficácia da educação.

Em estudo decisivo sobre a qualidade da educação na África, desenvolvido pela Associação para o Desenvolvimento da Educação na África (ADEA, 2004), o fator linguístico é um dos mais determinantes. Apesar dos mais de 50 anos após a primeira declaração da UNESCO, e apesar de uma infinidade de livros, artigos, convenções, declarações e recomendações, e várias experiências conclusivas no uso de idiomas locais em educação e política, a maior parte dos países africanos continua utilizando o idioma do país colonizador.

A África é o único continente em que a maioria das crianças começa a escola utilizando uma língua estrangeira. Persiste o pensamento de que os idiomas internacionais amplamente utilizados (árabe, inglês, francês, português e espanhol) são os únicos caminhos para o avanço econômico. 
Consequentemente, a escolha do idioma, o reconhecimento e seu papel no sistema educacional, o desenvolvimento do potencial expressivo e a acessibilidade ao público não devem seguir um princípio de exclusão, mas resultar de abordagem progressiva, concêntrica e global.

Graças a um ambicioso projeto denominado Elan-Afrique ${ }^{2}$, as crianças beninenses não apenas receberiam conhecimentos no idioma francês, mas igualmente na língua materna, o que ajudaria a melhorar a qualidade da educação.

A criança aprende melhor na língua materna do que em qualquer idioma, razão que motivou o país a aderir à iniciativa Elan (escola e idioma nacionais), que reúne oito países da África Subsaariana de língua francesa: Burkina Faso, Camarões, Mali, Níger, Senegal , Burundi, República Democrática do Congo e Benim (AKPO, 2012). O projeto visa promover e gradualmente introduzir a educação bilíngue na escola primária.

Em nível cognitivo, pesquisas sobre educação bilíngue atestam que as habilidades acadêmicas adquiridas na língua materna facilitam a aquisição de lições na língua francesa. No âmbito cultural, seria promovido o conhecimento da cultura, graças ao bom conhecimento da língua francesa.

As seguintes perguntas foram formuladas: qual a importância da introdução de línguas nacionais no sistema educacional formal do Benim? Essa introdução estaria livre de problemas?

\section{APRESENTAÇÃO, ANÁLISE, INTERPRETAÇÃO E DISCUSSÃO DOS RESULTADOS}

Para atingir o objetivo da pesquisa adotamos a abordagem metodológica que combina o método qualitativo à pesquisa por entrevista.

O método é voltado à população-mãe, composta por atores diretamente envolvidos (crianças em idade escolar, pais de alunos, professores, gerentes e pessoas com recursos financeiros). A maioria das informações buscadas foi obtida e os resultados registrados na tabela a seguir:

Tabela 1: Apresentação sintética dos resultados qualitativos

\begin{tabular}{|l|l|}
\hline \multicolumn{1}{|c|}{ Tema } & \multicolumn{1}{|c|}{ Resultados das questões da entrevista } \\
\hline Importância das línguas nacionais no processo & - Cultura valorizada \\
de desenvolvimento geral e no sistema & - Herança cultural intangível de um povo \\
educativo formal em particular & - Vetores da cultura de uma comunidade \\
& - Representam a existência de um povo \\
& - Fatores de desenvolvimento \\
& - Permitem a facilitação de entendimento \\
& - Permitem ao professor e ao aluno enriquecer \\
& O vocabulário \\
& - Permitem melhorar as taxas de sucesso \\
\hline Dificuldades ligadas à introdução das línguas & - Problema de engajamento político \\
nacionais & - Insuficiência de materiais didáticos \\
& - Problema de terminologia nos professores e \\
& alunos \\
& - Problema de silabação e fonética \\
& - Problema de ordem organizacional \\
& - Problema de recurso financeiro \\
& - Problema de ordem financeira \\
\hline
\end{tabular}

2 Disponível em www.elan-afrique.org. 


\begin{tabular}{|l|l|}
\hline & - Insuficiência de ordem financeira \\
\hline Sugestões para melhorar as línguas nacionais & - Verdadeiro engajamento político \\
& - Reciclagem regular do ensino experimental \\
& - Dar mais atenção à concepção dos \\
& documentos pedagógicos de línguas nacionais \\
& - Participação de professores experimentados \\
& nas concepções dos documentos pedagógicos \\
& de línguas nacionais \\
& - Investir muito mais dinheiro nos meios \\
& financeiros \\
\hline
\end{tabular}

Fonte: Elaboração dos autores

S. $\mathrm{B}^{3}$ ressaltou: as linguas nacionais representam a cultura verbalizada do homem ${ }^{4}$. Para N. D, é a herança cultural intangivel de um povo (entrevista em 28 de julho de 2014). Acrescentou: facilitam a compreensão e melhoram as taxas de sucesso dos alunos (N. D, entrevista em 28 de julho de 2014).

Mas existem relevantes problemas: terminológicos, compromisso político, assuntos organizacionais e insuficiência de material didático. Confirmados por S. B: temos material de ensino insuficiente para ensinar genuinamente as liçöes. Existem problemas de terminologia, tanto no nosso nivel como no nivel dos alunos, os problemas de silabação fonética (S. B, entrevista em 29 de julho de 2014). E meios financeiros, como D. A assinalou: existem os problemas de meios financeiros (D. A, entrevista em 27 de julho de 2014).

Por fim, os entrevistados fizeram sugestões, como D. A: é preciso compromisso politico, isso está claro. O governo e seu líder devem saber que as questões linguísticas são fundamentais. Não pode haver desenvolvimento sem valorizar as linguas nacionais (D.A, entrevista em 27 de julho de 2014). Além disso, para S. B, é preciso haver reciclagem regular do professor experimental; revisar a fase do conteúdo do programa (S. B, entrevista em 29 de julho de 2014).

Os dados levantados nos permitem resumir em dois resultados importantes, que apresentamos abaixo:

- A relevância das línguas nacionais no processo de desenvolvimento de uma nação e no sistema educacional formal do Benim.

- As dificuldades associadas à introdução no sistema educacional formal beninense.

A relevância das línguas nacionais no processo de desenvolvimento de uma nação e no sistema educacional formal do Benim

Cem por cento dos entrevistados reconhece que o tema é significativo. Demonstram-no a secretária-técnica permanente da Comissão Diretora Nacional para o assunto educacional formal e D. A, quando afirmam: os idiomas nacionais são ferramentas para o desenvolvimento (entrevista em 27 de julho de 2014). A. A, consultor técnico em alfabetização, acrescenta: a linguagem é o vetor de toda cultura, possibilita transportar a materialização de cultura de uma comunidade ou de um povo. É uma das riquezas intangiveis que o homem possui e que o torna um ser em sua comunidade (entrevista em 26 de julho de 2014).

Para Boko (1999), uma escola em que o acesso ao conhecimento inclui uma língua estrangeira literalmente dispensa o aluno da alavanca essencial do momento da apropriação e o afasta da cultura de origem, antes de servir como substrato.

\footnotetext{
${ }^{3}$ Os entrevistados são identificados pelas iniciais: S. B; D. A; A. A etc.

4 As falas dos entrevistados estão em itálico, diferenciando-as das citações bibliográficas.
} 
A aquisição sustentável de habilidades e conceitos científicos ocorreria em língua que se domina. Sobre o assunto, A. A, consultor técnico de alfabetização e introdução de línguas nacionais, afirmou:

Em qualquer sistema educacional em alguns países é necessário que o ensino seja dado na língua do meio para que o aluno possa já começar fazendo estes primeiros passos de ensino/aprendizagem com a língua, que é a que transmite realidades socioculturais. Isso é ainda mais importante, pois manter a integridade no ambiente torna possível evitar esforços adicionais. Em geral, muitos estudos têm mostrado que a educação na primeira língua melhora a qualidade da educação. Geralmente há bons resultados (entrevista em 26 de julho de 2014).

Poth (1990, p. 10) reitera: “[...] os psicólogos nos mostraram claramente que reprimir a fala materna de uma criança é extremamente prejudicial para o desenvolvimento das atividades cognitivas. Isso está prejudicando o desenvolvimento de suas habilidades linguísticas não nativas, que ele aprenderá mais tarde".

Adapta-se o indivíduo ao ambiente, enquanto o prepara ativamente para a vida econômica. Consistindo principalmente de pequenas indústrias locais, varejo, agricultura, pecuária e artesanato, expressa-se quase exclusivamente nas línguas nacionais, pois o sucesso nas diversas atividades exige bons conhecimentos dessas línguas (GUEDOU, 1987).

Conclui-se que a promoção da língua nacional permite o desenvolvimento endógeno local, porque a população da base ficaria ciente dos potenciais por meio do ensino da língua, confirmado por D. A:

O algodão cresceu, eu diria que é ótimo para o desenvolvimento econômico de nosso país, e estamos concentrando nossa atenção nele. Se estamos lá, é graças às línguas nacionais. Como você vai me perguntar? $\mathrm{O}$ primeiro que trabalhou com comunidades em Borgou em questões de alfabetização reuniu essas comunidades. Esta em que existe um famoso cavalheiro que ficou aqui chamado professor Elvet - paz em sua alma. Foi ele quem organizou os cotonicultores de Borgou por meio de atividades de alfabetização para mostrar a eles que, quando essas pessoas são alfabetizadas, não serão mais enganadas ou roubadas, e ele as organizou para que as atividades de alfabetização pudessem manter a contabilidade, seu saldo, porque os pobres produtores de algodão não sabem ler. Se produzem cinco toneladas, é dito, por exemplo, que produziram duas toneladas; nós os comemos, os roubamos. Desde que essas pessoas tenham sido treinadas, elas sabem equilibrar, ler e escrever, acabam com a desonestidade intelectual daqueles que as supervisionam, enganam. Isso lhes permitiu recuperar os déficits nesse meio tempo. E como sabem ler e escrever, eles aprenderam o básico de um grupo sólido para poder plantar grandes áreas, e sabem como manter suas contas. É assim que o crescimento do algodão está decolando no Norte (entrevista em 27 de julho de 2014).

O indivíduo que não domina a própria língua não pode pretender dominar a língua de outras pessoas. A melhor solução para o aprendizado efetivo das línguas nacionais nada mais seria do que o uso de línguas nacionais como idioma de instrução. No início da escolaridade, as crianças floresceriam utilizando a língua materna, porque apenas ela permitiria fazer perguntas e responder. A participação nas aulas seria eficaz. Madi (2011, p. 121) demonstra: "[...] acho que se poderia cultivar melhor a inteligência dos alunos e, com mais segurança, alcançar o objetivo de sua educação se se começasse estudando a língua materna".

Quanto aos aspectos sociais e familiares, uma língua nacional permitiria que a família acompanhasse o progresso educacional do aluno, interessando-se por seu trabalho. A família 
continuaria no esforço educacional desenvolvido no ambiente familiar e participaria da educação das crianças, garantindo que os valores tradicionais sejam levados em consideração na escola.

Nas aldeias nas quais os adultos têm um centro de alfabetização há interação positiva com a escola bilíngue, acarretando melhor progresso dos dois tipos de aprendizado. Uma criança matriculada em uma escola bilíngue se tornaria um trabalhador de alfabetização quando adulto. Como resultado, seriam resolvidas as dificuldades de treinar pessoas alfabetizadas em francês para serem alfabetizadores no idioma nacional, enviando-as às aldeias nas quais nasceram.

Entretanto, mesmo que a introdução tenha vantagens, permanece a certeza de que enfrentaria grandes problemas.

As dificuldades relacionadas à introdução de línguas nacionais no sistema formal de educação beninense

Nas razões organizacionais, $15(83,33 \%)$ dos pesquisados afirmaram ter havido uma "multidão" de grupos linguísticos nas escolas primárias. A integração requer a organização perfeita dos diferentes grupos linguísticos presentes, e as situações dificultam a aplicação dessa política. $\mathrm{N}$. $\mathrm{D}$ declarou que não podemos ter uma linguagem real na qual vamos trabalhar, mas existem linguas que foram trabalbadas e que poderiam ser essenciais, mas é simplesmente bom que eu pertença a um grupo étnico e não devo deixar minha lingua morrer, portanto, não consigo entender a linguagem do outro (entrevista em 28 de julho de 2014).

Há alunos que não entendem os idiomas em vigor no distrito escolar, e aqueles que entendem todas as línguas utilizadas, "mergulhados" no embaraço da escolha e expostos ao risco de instabilidade, dificultando a atribuição a um grupo linguístico escolar.

A introdução implica dificuldades didáticas. $O$ aluno, na presença de duas línguas de instrução, será confrontado com o problema da interferência linguística, com efeitos na expressão, se medidas didáticas não forem tomadas. Existe, portanto, o risco de interpretações subjetivas de um idioma para outro, tornando "pobre" o nível de ensino em qualquer um dos idiomas de instrução. E ocorre ainda a insuficiência de materiais de ensino para, genuinamente, serem ministrados cursos em idiomas nacionais.

Sobre assuntos políticos, vinculam-se, por um lado, à unidade nacional, que exige o monolinguismo oficial. Portanto, várias línguas nacionais na educação seria um "freio" nessa unidade. O uso difundido e dominante das línguas nacionais traria riscos de isolamento e resultaria, talvez, em um nível insuficiente de domínio das línguas europeias. Surgiriam, ainda, os preconceitos herdados da colonização.

No raciocínio da maioria das elites, reivindicações como as línguas africanas não serão capazes de transmitir conhecimento moderno. Somente as línguas europeias o fizeram, abrindo caminho para o progresso e a modernidade; $50 \%$ dos entrevistados o confirmam. A. A, consultor técnico de alfabetização e introdução de línguas nacionais, enfatizou: herdamos vestígios de coloniz̧ação da França, o que significa que pensamos que as linguas nacionais são estranbas, quando na realidade muitos estudos têm mostrado que as linguas nacionais garantem a qualidade da educação (entrevista em 26 de julho de 2014).

Quanto aos problemas de terminologia, 12 pessoas entrevistadas (66,66\%) concordaram que muitos estudantes não conseguem encontrar palavras corretas para se expressar no idioma nacional. D. A ressaltou:

Outra dificuldade, a abordagem; o fórum pediu que introduzíssemos os idiomas como material de ensino, ou seja, os idiomas serão ensinados à medida que ensinamos inglês ou francês. Então, como veículo de conhecimento, mas nos encontramos em um contexto ou após o estudo de idiomas e escolaridade na África, os franceses da OIF e seu Ministério de Relações Exteriores queriam os 
oito Estados identificados, como Benim, Burkina-Faso, Níger, Mali, Senegal etc. Estão começando a experimentar idiomas no sistema educacional, mas como veículo para o ensino, ou seja, como um meio. De repente, fomos confrontados com certas dificuldades porque era necessário definir um certo número de terminologias, era necessário evitar os problemas de metalinguagem, e essas dificuldades não foram suficientemente resolvidas antes de começarmos, mas existem problemas que serão gerenciados (entrevista em 27 de julho de 2014).

As observações atestam que os argumentos contra o uso de línguas nacionais nas escolas são os mesmos dos demais países africanos, apresentados sempre que o status das línguas nacionais é menor do que o da língua europeia. Outra observação seria o bem-sucedido exercício de Cheik Anta Diop (1979), que traduziu para Wolof textos científicos sobre teoria dos conjuntos, relatividade e química, que faz parte da busca de respostas para argumentos semelhantes.

\section{CONCLUSÃO}

A introdução de idiomas nacionais na educação demonstra ser de longo prazo, processo que requer paciência e vigilância. Embora se enfatize a premência da reforma do sistema formal de educação beninense, implica ser precedido ou acompanhado por preparação significativamente apropriada. Para a reforma se mostrar eficaz, deve haver certo número de etapas com tarefas a serem cumpridas. Consistiriam no desenvolvimento de uma política objetiva de linguagem, trabalho de pesquisa linguística, produção de documentos educacionais e didáticos, adesão de todos os gerentes aos programas.

E a fim de ser efetiva no sistema educacional, tem-se que buscar o envolvimento dos atores políticos e administrativos, e pesquisadores, como andragogos, linguistas, sociólogos, especialistas em planejamento e gestão educacional etc., além de professores de todos os níveis.

Quanto aos problemas didáticos, treinamento na didática das distintas disciplinas seria essencial em um contexto bilíngue ou multilíngue, a par de uma consistente conscientização sobre possíveis interferências linguísticas.

Nos problemas relacionados aos assuntos políticos, deve haver verdadeiro engajamento do governo em executar meios para o projeto. Seria estabelecida uma estratégia de comunicação para informar a população sobre a importância do tema em canais de comunicação (televisão, rádio, internet etc.), com uma política linguística explícita.

Quanto à formação de professores, deve-se treinar novamente professores experientes. E considerar módulos de treinamento no sistema educacional nas Escolas Nacionais de Professores e Escolas Normais Superiores. Os professores as deixarão bem equipadas, com treinamento adicional de várias formas em cursos e seminários de atualização.

Nos problemas de terminologia, o Estado disporia dos meios para a efetivação lexical e a unificação terminológica. Os estudos continuariam nessa direção para haver vocabulários próprios.

Dos entrevistados, todos reconheceram a relevância do tema, o que permitiu confirmar a hipótese inicial - a introdução de idiomas nacionais no sistema educacional beninense contribui para o desenvolvimento e a escolaridade de crianças, com bons resultados acadêmicos.

\footnotetext{
${ }^{5}$ Wolof é uma língua falada na África Ocidental, pertencente à etnia wolof, da família linguística nígero-congolesa, presente no Senegal, Gâmbia, Mauritânia, Guiné-Bissau e Mali.
} 


\section{REFERÊNCIAS}

ADEA (Association pour le développement de léducation em Afrique). La quête de la qualité: à lécoute des expériences africaines. Biennial Meeting: Grand Baie, Mauritius. Association for the Development of Education in Africa, 2004.

ADJADOHOUN, Romaric. Problématique de l'adaptation des langues nationales aux savoirs modernes. Mémoire de maitrise de linguistique l'UNB. 113p., 1991.

ADJIBODOU, Aristide Adebayo. L'enseignement/ apprentissage en langues nationales: une alternative au renforcement des compétences intellectuelles pour un développement durable. Université d'Abomey-Calavi, 2006.

AFELI, Kossi. Les langues africaines et le développement de l'Afrique. In: Langage et Pédagogie, n. 6, Revue du labodel, CEBELAE, p. 9-22, 1987.

AKOHA, Albert Bienvenu. Quelle stratégie pour lintroduction des langues béninoises au Bénin. In: CAPO, Hounkpati Christophe; GBETO, Flavien; HUANNOU, Adrien. Les langues africaines dans lenseignement au Bénin: problème et perspectives. Pub Labo Gbe n. 9, 1999.

AKPO, Georges. Système éducatif béninois: les langues nationales seront enseignées à l'école à la rentrée prochaine: la Françafrique lâche du lest? In: Babilown Mawolè. 9 out. 2012. Disponível em https://blaisap.typepad.fr/mon weblog/2012/10/systme-ducatif-bninois-les-langues-nationalesseront-enseignes-lcole-la-rentre-prochaine.html. Acesso em 11 ago. 2015.

BENIN (République du Bénin). Constitution de la République du Bénin. 11 de décembre 1990. Disponível em https://www.wipo.int/edocs/lexdocs/laws/fr/bj/bj001fr.pdf. Acesso em 15 jan. 2020.

BOKO, Gabriel. Importance de la langue maternelle dans le développement psychomoteur, affectif, et cognitif de l'enfant et ses importances dans la vie scolaire. In: Langage et Devenir, n. 11. Cotonou, p. 2-14, 2007.

BOKO, Gabriel. Les huit, n. 8. Entretiens sur le BAIP 1998-1999, Flash-UNB. Cotonou, 1999.

CALVET, Louis-Jean. Les langues nationales à lécole: débat passionné, un serpent de mer. In: Dialogue, n. 2, p. 22-24, 1992.

CARVALHO, José Carlos de Paula. Rumo a uma Antropologia da Educação: Prolegômenos I. In: Revista da Faculdade de Educação, n. 2, v. 8. São Paulo: Faculdade de Educação da Universidade de São Paulo, 1982a, p. 113-132. Disponível em http://educa.fcc.org.br/pdf/rfe/v8n2/v8n2a02.pdf. Acesso em 11 ago. 2019.

CARVALHO, José Carlos de Paula. Rumo a uma Antropologia da Educação: Prolegômenos II. In: Revista da Faculdade de Educação, n. 2, v. 10. São Paulo: Faculdade de Educação da Universidade de São Paulo, 1982b, p. 257-283. Disponível em http://educa.fcc.org.br/pdf/rfe/v10n2/v10n2a06.pdf. Acesso em 11 ago. 2019.

CARVALHO, José Carlos de Paula. Derivas e Perspectivas em torno de uma Sócio-antropologia do Cotidiano. In: Revista da Faculdade de Educação, n. 12, v. 1-2. São Paulo: Faculdade de Educação da Universidade de São Paulo, 1986, p. 85-105. Disponível em http://educa.fcc.org.br/pdf/rfe/v12n1-2/v12n1-2a05.pdf. Acesso em 11 ago. 2019.

DIOP, Cheik Anta. Nations, nègres et cultures. Tome 2. Présence Africaine, 1979.

DIKI-KIDIRI, Marcel. Le Sango en Centrafique aujourd hui. In: Université, 1992. 
GNAHO, Christelle. La problématique du bilinguisme et du multilinguisme en contexte scolaire au Bénin: Etats des lieux et perspectives. Mémoire de maitrise, Département des Sciences du Langage et de la communication, Université dAbomey-Calavi, 2011.

GUEDOU, Georges Gangbe. Langues africaines, écriture et développement. In: Langage et devenir, n. 6, p. 63-93, 1987.

GUEYE, Pape Samba. Analyses des blocages de l'introduction des langues nationales dans l'enseignement élémentaire formel au Sénégal: étude dans la commune de Fatick. Mémoire pour lobtention du master I en lettres et sciences humaines à l'Université Gaston Berger de Saint-Louis. 2010.

LEKOYO, Bouraïma. Introduction des langues maternelles dans l'enseignement au Bénin: problèmes et approches de solution. Mémoire de fin de formation pour lobtention du CAPEM en Lettres Modernes à l'Ecole Normale Supérieure de Porto-Novo, 1988.

LIETTI, Anna. Pour l'éducation bilingue: guide de survie à l'usage des petits européens. Paris: Paperback, 1989.

MADI, Haladi. La diversité des langues à Mayotte et les problèmes scolaires consécutifs. In: Plurilinguisme, politique linguistique et éducation: Quels éclairages pour Mayotte? Mont-Saint-Again: Presses Universitaires de Rouen et du Havre, 2011.

OUANE, Adama. Vers une culture multilingue de léducation. Hambourg: Institut de IUNESCO pour lÉducation, 1995.

POTH, Joseph. Les langues africaines facteurs de développement. Douala: College Libermann, 1990.

ROLLAND, Dominique. Français langue étrangère ou français langue secondaire: un grand écart. Paris: Le Français dans le monde, 2010.

SIGUÀN, Miguel; MACKEY, William Francis. Educación y bilingüismo. Madrid: Santillana, 1986.

UNESCO (Organisation des Nations Unies pour l'Education la Science et la Culture). The use of vernacular languages in education. Paris: United Nations Educational, 1953.

Submetido em marco de 2020

Aprovado em julbo de 2020

\section{Informações dos autores}

Julvan Moreira de Oliveira

Doutor em Educação pela Universidade de São Paulo (USP); Professor do Programa de Pós-graduação em Educação da Universidade Federal de Juiz de Fora (UFJF).

E-mail: julvan.moreira@ufjf.edu.br

ORCID: http://orcid.org/0000-0003-1815-6268

Link Lattes: http://lattes.cnpq.br/0381026342612680

Narcisse Sylvestre Sègla Adjoudeme

Doutorando em Sociologia-Antropologia pela Universidade de Abomey-Calavi, Benim, doutorando sanduíche reverso no Programa de Pós-graduação em Educação da Universidade Federal de Juiz de Fora (UFJF).

E-mail: adjoudemenarcisse@gmail.com 
ORCID: https://orcid.org/0000-0002-8638-0643

Link Lattes: http://lattes.cnpq.br/9669637958986461 